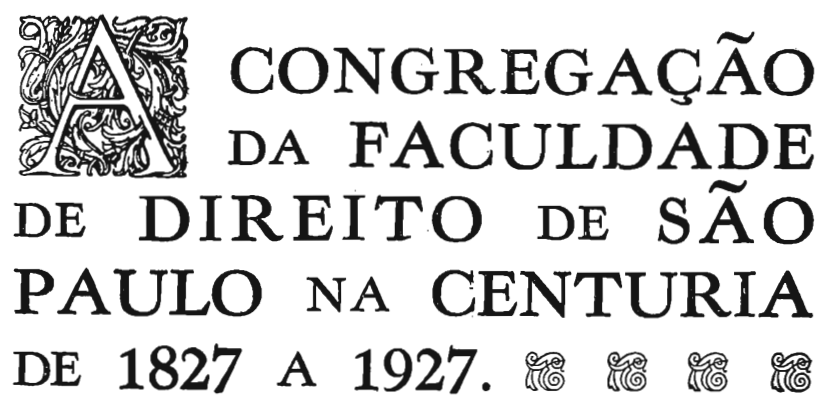

Notas compiladas e coordenadas pelo Dr. WALDEMAR FERREIRA, professor cathedratico de Direito Commercial. 


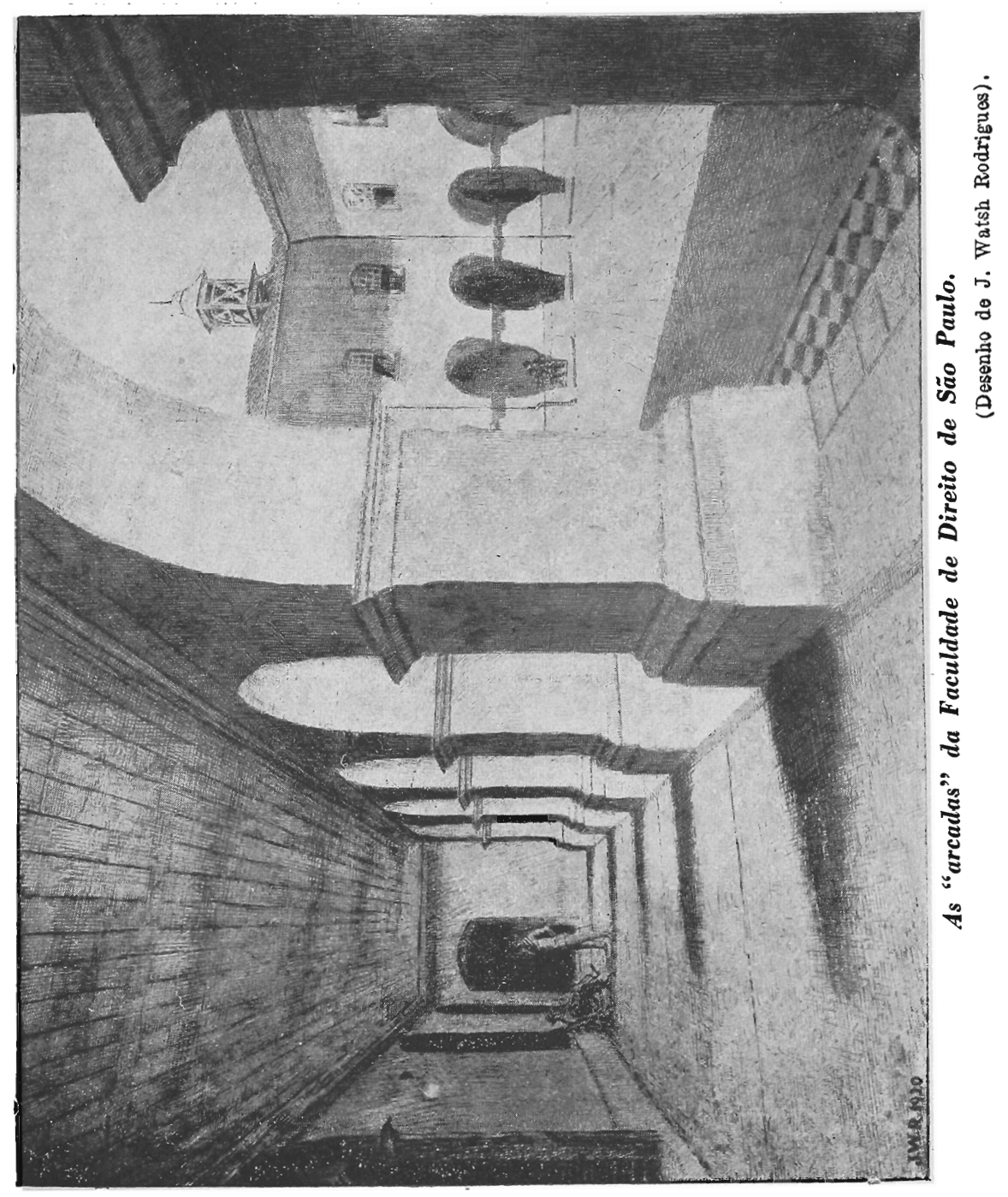


Este trabalho é uma compilação, para a qual foram de inestimavel prestancia as Tradições e Reminiscencias, do DR. J. L. DE ALMEIDA NOGUEIRA, e a Memoria para a historia da Academia de São Paulo, do DR. SPENCER VAMPRE', os dois notaveis historiadores da Faculdade de Direito de São Faulo.

De não menor relevancia foi o contingente do BEL. JULIO DE BARROS, zeloso e competente funccionario, que tem a seu cargo o Archivo da Faculdade de Direito, que elle vem reconstituindo, com benedictina paciencia, dos salvados do incendio de 1880. Muitas de suas notas foram não somente aproveitadas, como transcriptas, em muitos passos. 


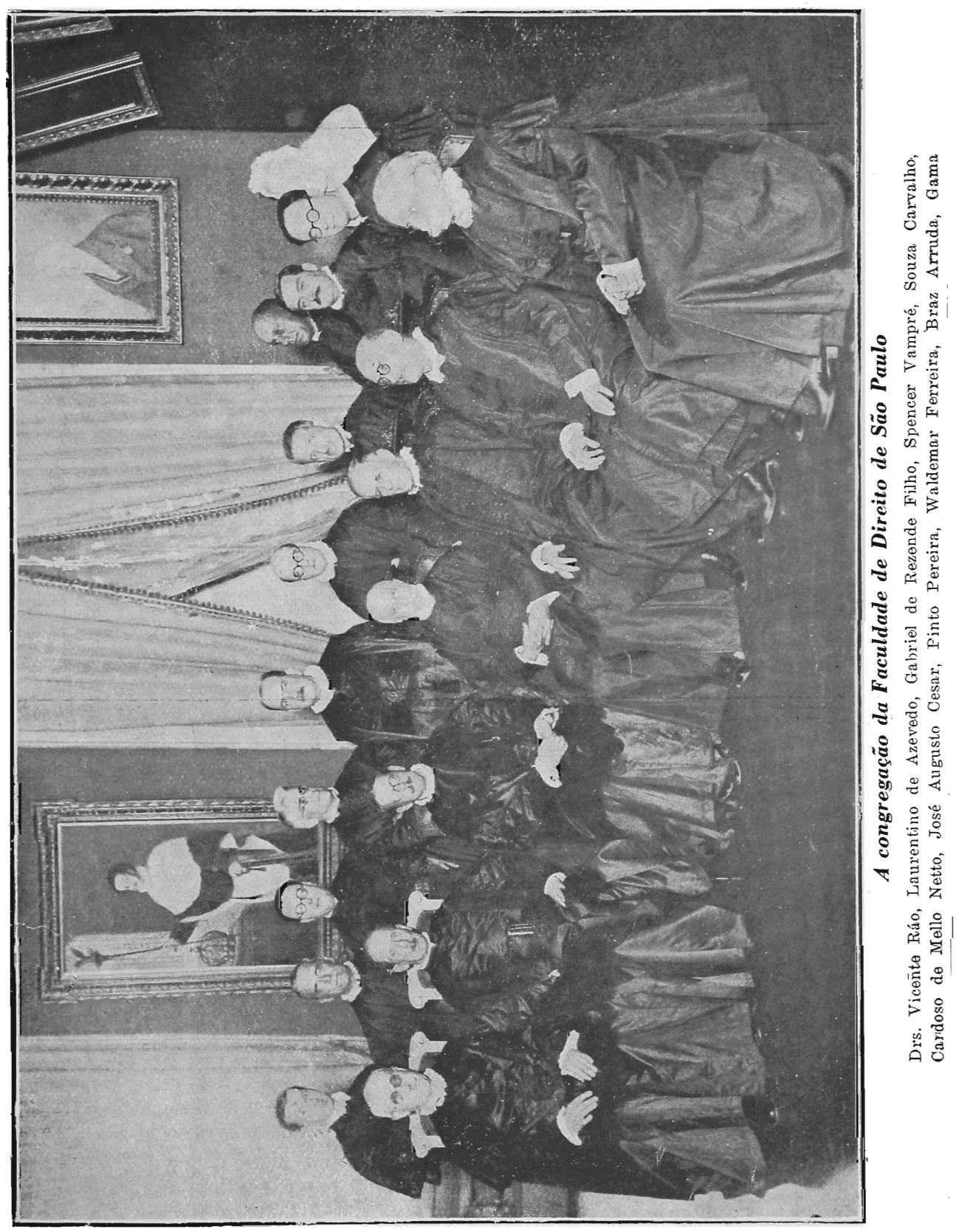


I

OS DIRECTORES 


\section{TENENTE GENERAL DR. JOSÉ AROUCHE DE TOLEDO RENDON}

\section{(1827 a 1833)}

Nasceu na cidade de São Paulo, aos 14 de março de 1756, fillho do mestre de campo Agostinho Delgado Aroutche e de D. Maria Thereza de Araujo Lara.

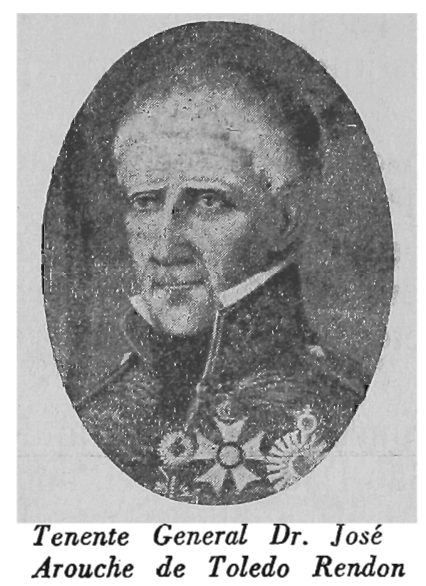

Fez o curso de direito civil em Coimbra, onde recebeu o grau de doutor em leis, em 14 de julho de 1779. De volta ao Brasil, abriu a sua banca de advogado em São Paulo. Serviu, depois, os cargos de juiz de medições, de juiz ordinario, de juiz de orphams e de procurador da Corôa. E os serviu com proficiencia e honradez.

Sentindo-se attraido pela carreira das armas, assentou praça no estado maior do exercito, no posto de capitão. Galgou, nella, todos os postos, pois foi mestre de campo, inspector geral de milicias, brigadeiro, marechal de campo e, por decreto de 18 de outubro de 1829 , tenente-general. Da sua inspecção ás aldeias de indios, existentes na provincia, deixou um relatorio, que corre impresso.

Adepto da causa da independencia, foi, em janeiro de 1822, como delegado da Camara Municipal de São Paulo, enviado ao Rio de Janeiro, em missão junto ao Principe Regente, D. Pedro, para solicitar-lhe que desobedecesse aos chamados das Côrtes de Lisbôa e ficasse no Brasil. Fizeram parte dessa missão, tambem, o Coronel 
Gama Lobo e, por parte do Governo Provisorio, José Bonifacio de Andrada e Silva.

Por decreto de 20 de maio de 1822, foi nomeado commandante das armas de São Paulo. Feita a Independencia e convocada a Assembléa Constituinte, foi eleito deputado por São Paulo, com José Bonifacio, Antonio Carlos, Paula Souza, Nicolau Vergueiro, José Ricardo de Andrade, Fernandes Pinheiro, Velloso de Oliveira e Diogo Ordonhes, tendo sido este ultimo substituido por José Corrêa Pacheco e Silva. Na Assembléa, tomou parte nas discussões em torno da indicação de Fernandes Pinheiro sobre a creação da Universidade de São Paulo.

Eleito deputado geral para a legislatura de 1826 a 1829 , não tomou assento e foi substituido pelo brigadeiro José Vicente da Fonseca.

Por decreto de 13 de outubro de 1827, foi nomeado director do Curso Juridico de São Paulo, que installou em 1 de março de 1828 , nelle permanecendo até 1833 , quando, attendendo a insistentes pedidos seus, o governo imperial lhe concedeu exoneração, por decreto de 31 de outubro de 1833.

Prestou o tenente general Arouche Rendon grandes serviços á cidade e á provincia de São Paulo, e o seu nome condecora a rua, que sae da Praça da Republica e vae dar no largo, que tem o seu nome, aberta na grande chacara, onde elle residia, e que the pertencia, no bairro da Villa Buarque.

Falleceu em São Paulo aos 26 de junho de 1834.

Obras publicadas:

- Memoria sobre as Aldeias de Indios da Provincia de São Paulo, na Revista do Instituto Historico e Geographico Brasileiro, vol. 4;

- Elementos de Processo Civil, precedidos de instrucções para os juizes municipaes. Typographia do Governo, no Palacio. São Paulo, 1850. 
2. CONSELHEIRO DR. CARLOS CARNEIRO DE CAMPOS (Visconde de Caravellas)

\section{(1833 a 1835)}

Natural da Bahia, nasceu Carlos Carneiro de Campos, o terceiro Visconde de Caravellas, em 1 de novembro de 1805. Serviu como cadete no batalhão de D. Pedro I.

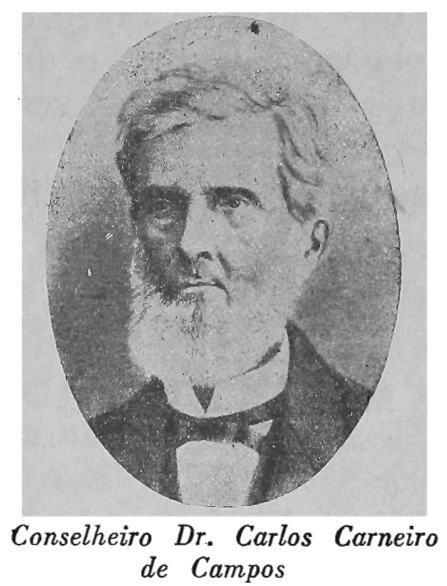

Frequentou a Escola Militar. Cursou a Universidade de Coimbra, onde se graduou em direito. Nomeado, por decreto de 9 de fevereiro de 1829; lente cathedratico de economia politica, primeira cadeira do quinto anno, tomou posse em 13 de maio de 1829; mas o aviso de 10 de fevereiro do mesmo anno, do ministro do Imperio, José Clemente Pereira, determinou que fosse servindo como substituto interino, emquanto se não verificasse o exercicio da sua cadeira. Serviu, tambem, interinamente, de secretario, de fevereiro de 1832 a 19 de agosto de 1833, data em que passou a director interino, exercendo este cargo até 24 de outubro de 1833, em que foi nomeado inspector do Thesouro.

Por decreto de 24 de dezembro de 1833 , foi nomeado director effectivo, tomando posse a 27 do mesmo mez. Exerceu o cargo até 5 de novembro de 1835.

Fundou a Sociedade Philomatica, de cuja revista foi director, em companhia de Francisco Bernardino Ribeiro e José Ignacio Silveira da Motta e outros.

Foi jubilado por decreto de 29 de janeiro de 1858.

Deputado á Assembléa Provincial da Bahia, deputado geral e senador por São Paulo, desde 19 de abril de 1853, presidiu, por tres vezes, a provincia de Minas Geraes. Foi vice-presidente de São Paulo, em 1852. Occupou a pasta dos Estrangeiros nos gabinetes de 24 
de maio de 1862 , de 31 de agosto de 1864 , de 7 de março de 1871, e a pasta da Fazenda no gabinete de 31 de agosto de 1864.

Recebeu os titulos de Conselheiro de Estado, Veador de Sua Magestade a Imperatriz, Commendador da Ordem de Christo, Grão Cruz das Ordens de Leopoldo da Belgica, da Legião de Honra da França, da Aguia Vermelha da Allemanha, da Corôa da Italia, da Corôa de Ferro da Austria, da Ernestina, de Saxe Coburgo e Gotha, o que demonstra os altos serviços prestados ao Brasil e os seus grandes meritos.

Falleceu, com mais de 80 annos, em 19 de fevereiro de 1878.

\section{CONSELHEIRO DR. JOSÉ DA COSTA CARVALHO (Marquez de Monte Alegre)}

\section{(1835 a 1836)}

Filho legitimo do patrão mór da barra da cidade de S. Salvador da Bahia, José da Costa Carvalho, e de D. Ignez Maria da Piedade, naquella cidade nasceu. For-

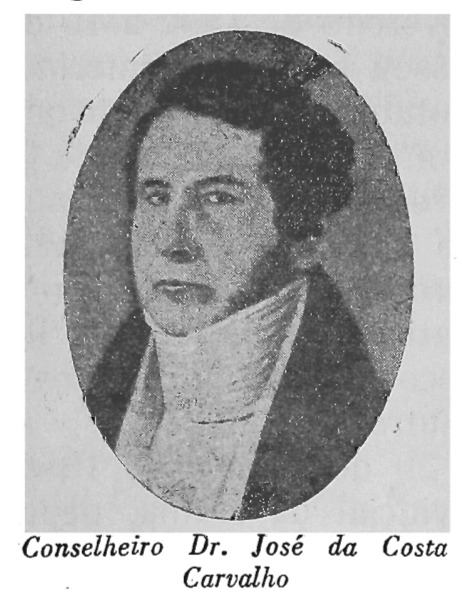
nardo de Vasconcellos e Honorio Hermeto Carneiro Leão Fundou $O$ Farol Paulistano. mou-se em leis na Universidade de Coimbra, em 1819. Dalli veiu despachado para o Brasil juiz de fóra da cidade de São Paulo, da qual foi ouvidor, de 1821 a 1822 .

Constituiu familia em São Paulo, contraindo casamento com D. Genebra de Barros Leite, de importante e conceituada familia paulistana. Encabeçou o partido liberal, sendo companheiro de Feijó, Paula e Souza, Evaristo da Veiga, Ber- 
Tomou parte na Constituinte e na Assembléa Legislativa, como deputado, na primeira, segunda e quarta legislaturas.

Com a Abdicação de D. Pedro I, fez parte da Regencia Permanente.

Por decreto de 5 de novembro de 1835, foi nomeado director do Curso Juridico de São Paulo. Tomou posse em 5 de dezembro e exonerou-se por decreto de 24 de Junho de 1836, servindo apenas seis mezes e alguns dias.

Foi agraciado com o titulo de Barão de Monte Alegre, em 1841; com a carta de Conselheiro de Estado, em 1842; com o titulo de Visconde, em 1843; com o de Marquez, em 1854.

Organizou os gabinetes de 1848 e de 1852 .

\section{CONSELHEIRO Dr. NICOLAU PEREIRA DE CAMPOS VERGUEIRO}

\section{(1837 a 1842)}

Filho do Dr. Luiz Bernardo Vergueiro e de D. Clara Maria Borges de Campos, nasceu aos 20 de dezembro de 1778, em Val de Porca, antigamente comarca de Chacin,

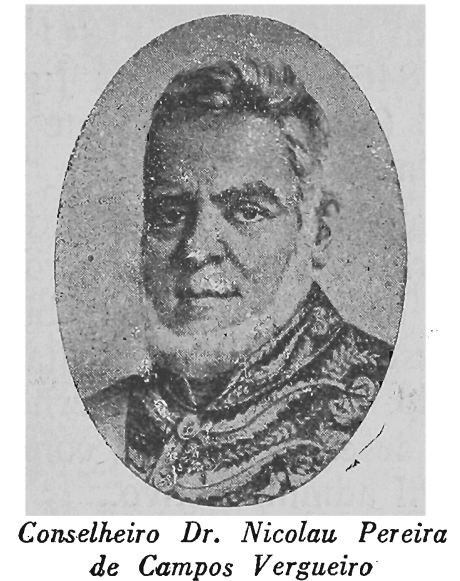
de Campos Vergueiro Paulo. Aqui, em 1804, contraiu
matrimonio com D. Maria Angelica de Vasconcellos, filha

hoje Macedo de Cavalleiros, na provincia de Traz-os-Montes, bispado e comarca de Bragança, em Portugal.

Feitos os estudos menores no Real Collegio das Artes, com assento na Universidade de Coimbra, matriculou-se nesta universidade aos 5 de outubro de 1876, doutorando-se em leis a 11 de julho de 1801. Formado, veiu para o Brasil, em 1803, fixando-se em São Angelica de Vasconcellos, filha 
do capitâo José de Andrade e Vasconcellos e de D. Anna Eufrosina de Cerqueira Camara. No fôro paulistano militou como advogado ao lado dos drs. Manoel Euphrasio de Azevedo Marques, José Arouche de Toledo Rondon e Manoel Joaquim Ornellas, que eram, então, os unicos advogados em São Paulo. Advogou até 1815. Foi juiz das sesmarias, até 1816, quando se retirou para Piracicaba afim de dirigir os engenhos que alli fundou, de sociedade com o brigadeiro Luiz Antonio de Souza. De então em deante a sua actividade se desdobrou, prestando ao nosso paiz os mais assignalados serviços. Depois de ter sido promotor de residuos (1806) e juiz ordinario (1811), foi nomeado vereador da Camara Municipal de São Paulo (1813), membro do governo provisorio da provincia de São Paulo (1821), deputado á Constituinte Portuguesa (1822), deputado á Constituinte Brasileira (1823), deputado geral por São Paulo (1826 a 1828), senador por Minas Geraes (1828 a 1859), membro do Conselho do Governo de São Paulo (1826 a 1829 e 1830 a 1833), membro da Regencia Provisoria Trina (1831), ministro do Imperio (1832), ministro da Fazenda (1832), deputado á Assembléa Provincial de São Paulo (1835 a 1847), presidente da Assembléa Legislativa de São Paulo (1835 a 1837), grã-cruz da Imperial Ordem do Cruzeiro (1841), gentil homem da Casa Imperial (1846), ministro da Justiça (1847), ministro do Imperio (1847), presidente e membro do Conselho de S. M. o Imperador.

Desde que surgiram os projectos parlamentares relativos á fundação dos cursos juridicos, nelles cooperou Nicolau Vergueiro, intervindo nas discussões e contribuindo por que o projecto em lei fosse convertido. Installado o Curso Juridico de São Paulo, quando no governo, varias medidas suggeriu para o seu desenvolvimento, como a creação da cadeira de direito civil administrativo.

Foi nomeado director do Curso Juridico, por decreto de 28 de janeiro de 1837, do regente Feijó. Tomou posse em 13 de março do mesmo anno e exerceu o cargo durante 
cinco annos, do qual foi demittido por decreto de 10 de fevereiro de 1842.

Falleceu no Rio de Janeiro aos 18 de setembro de 1859.

\section{CONSELHEIRO PADRE DR. MANOEL JOAQUIM DO AMARAL GURGEL}

\section{(1858 a 1864$)$}

Nasceu em São Paulo aos 8 de setembro de 1797. Educado por sua parenta e madrinha, D. Maria Polucena do Amaral Gurgel, fôra, desde o berço, confiado aos ca-

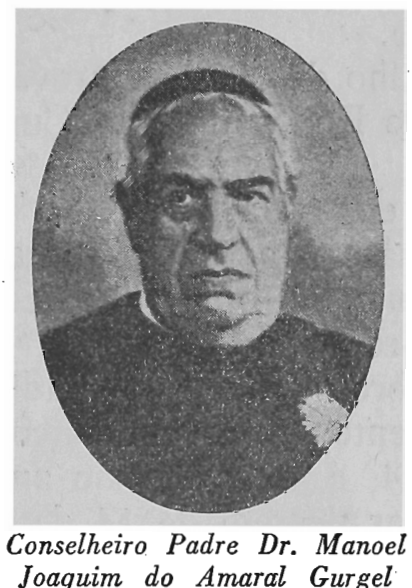
rinhos de D. Beatriz Leoniza do Amaral Gurgel, irman daquella.

Feito o seu curso de latim na aula regia do professor André da Silva Gomes, onde teve por collegas Vicente Pires da Motta, João Chrispiniano Soares, Joaquim Ignacio Ramalho, Ildefonso Xavier Ferreira, Raphael Tobias de Aguiar, e outros, matriculou-se no Curso de Theologia, installado no Convento do Carmo, sob a direç̧ão de Frei Antonio do Bom Despacho Mamede. No Convento de São Francisco, frequentou a aula de philosophia de Frei Francisco Mont'Alverne, o famoso orador sacro, em 1814. Recebeu, em 1816, as ordens de presbytero, já então professor de historia ecclesiastica no Seminario de São Paulo, figurando entre os mais fulgidos ornamentos do clero paulistano.

Em 1823, após a queda do ministerio Andrada e á dissolução da Assembléa Constituinte, começou o padre Manoel Joaquim a apparecer na politica liberal de São 
Paulo, quando foi deportado para o Rio de Janeiro, por ordem de D. Pedro I.

Installado o Curso Juridico de São Paulo, em 1828, nelle se matriculou, e foi dos mais salientes da primaira turma academica, o que não obstou a que já então fosse eleito membro do conselho geral da Provincia e do conselho do Governo. Depois do Acto Addicional, foi deputado provincial, consecutivamente, de 1834 a 1842 e no biennio de 1847 a 1848 . No quatriennio de 1834 e 1837 , tomou assento, como supplente, na Camara dos Deputados. Exerceu, ainda, como vice-presidente, o governo da Provincia, de 30 de junho a 25 de setembro de 1859; de 22 de outubro a 16 de novembro de 1860 ; de 14 de maio a 7 de junho de 1861 e de 3 de fevereiro á 7 de março de 1864.

Recebeu o titulo de Conselho.

Por carta imperial de 6 de julho de 1829, approvado em concurso, foi nomeado lente de Philosophia do Curso Annexo.

Recebeu o grau de bacharel em 1832.

A 1 de fevereiro de 1833, passou a exercer, interinamente, o cargo de lente substituto, no qual foi effectivado por decreto de 12 de outubro do mesmo anno, tomando posse em 15 de novembro. Tendo defendido theses e sido approvado plenamente, e unanimemente, recebeu o grau de doutor em 1834, e nesse mesmo anno foi nomeado lente cathedratico, por decreto de 14 de janeiro. Tomou posse a 27 de fevereiro da primeira cadeira do segundo anno.

Com a demissão do Senador Vergueiro, em 1842, ficou vaga, e por dilatado tempo, a directoria do Curso Juridico, por isso que, nomeado director naquella data, o Visconde de Goyana jamais tomou posse do cargo; e essa acephalia durou por mais de quinze annos. Foi o Padre Manoel Joaquim, em 1837, nomeado director interino, exercendo esse cargo até 1838. Por decreto de 1 de dezembro de 1857, foi nomeado director effectivo da $\mathrm{Fa}$ culdade de Direito, como passou a denominar-se o curso 
juridico, pelo decr. n. 714 , de 19 de setembro de 1853 , tomando posse em 1 de março de 1858 . Jubilou-se por decreto de 18 de maio de 1858, no cargo de lente.

Jamais, segundo o testemunho de Almeida Nogueira, teve a Academia director que melhor conciliasse com o respeito devido ao cargo a sympathia dos estudantes, a estima dos lentes e professores e a dedicação dos funccionarios seus subordinados na gerarchia administrativa.

Falleceu o Conselheiro Padre Dr. Manoel Joaquim do Amaral Gurgel em 15 de novembro de 1864, contando sessenta e sete annos de edade. Seu nome foi dado á rua que liga o largo do Arouche á rua da Consolação, na cidade de São Paulo.

\section{CONSELHEIRO PADRE DR. VICENTE PIRES DA MOTTA}

\section{(1865 a 1882)}

Natural de São Paulo, nasceu em 1779, filho de Manoel Antonio Pires da Motta. Quando se matriculou no primeiro anno do Curso Juridico, em 1828, já era presby-

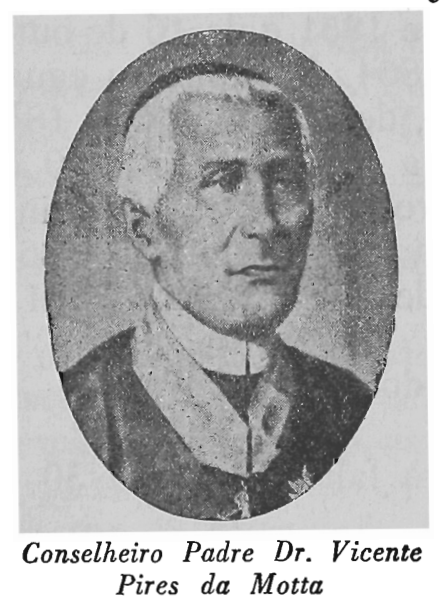
tero, e sua filiação foi dada como ignorada. Foi exposto na casa de Vicente Pires da Motta, antigo cirurgião, na rua Direita da cidade de São Paulo; mas quando foi restaurado, sob sua directoria, o archivo da Faculdade de Direito, destruido no incendio de 1880 , no livro da relação dos doutores e bachareis se declinou o nome de seu pae.

Recebeu o grau de bacharel em 1832 e, em 1 de fevereiro de 1833, foi nomeado lente substituto interino, seguindo a sorte de seus illustres collegas Manoel Joaquim do Amaral 
Gurgel e Manuel Dias de Toledo. Com elles, defendeu theses e recebeu o grau de doutor em 1833, como elles plena e unanimemente approvado. Effectivado por decreto de 7 de outubro de 1833, foi nomeado lente cathedratico de direito civil, primeira cadeira do quarto anno, por decreto de 27 de maio de 1834 .

Exerceu o cargo de director interino de abril de 1837 até abril de 1838.

Foi jubilado no cargo de lente cathedratico por decreto de 7 de agosto de 1860 .

Por decreto de 30 de janeiro de 1865 , foi nomeado director, tomando posse do cargo em 6 de fevereiro do mesmo anno.

De 1828 a 1834, foi eleito membro do conselho geral da provincia de São Paulo, membro do conselho do governo, e, depois desta data, deputado á Assembléa Provincial nos biennios de 1834-35, 1836-37, 1838-39, 1840-41.

Habil e principalmente rigido e austero administrador, esteve em diversas epocas, de 1834 a 1869 , á testa do governo da provincia de São Paulo, como seu vice-presidente, e, na qualidade de presidente effectivo, de 16 de outubro de 1848 a 27 de agosto de 1851 e de 16 de outubro de 1862 a 3 de fevereiro de 1864. Administrou egualmente a provincia de Pernambuco, de 26 de abril de 1848 a 17 de junho do mesmo anno; a do Ceará, de 20 de fevereiro de 1854 a 11 de outubro de 1855; a de Minas Geraes, de 13 de junho de 1860 a 2 de outubro de 1861 ; e a de Santa Catharina, de 17 de novembro de 1861 a 24 de setembro de 1862 .

Foi, em 1850, condecorado com o titulo de conselho.

O conselheiro Pires da Motta falleceu no dia 30 de outubro de 1882. 


\section{CONSELHEIRO DR. ANDRÉ AUGUSTO DE PADUA FLEURY}

\section{(1883 a 1890)}

Natural de Cuyabá, da provincia de Matto Grosso, filho do Tenente Antonio de Padua Fleury e de D. Augusta Rosa Gandel. Nasceu aos 18 de agosto de 1830. Tendo

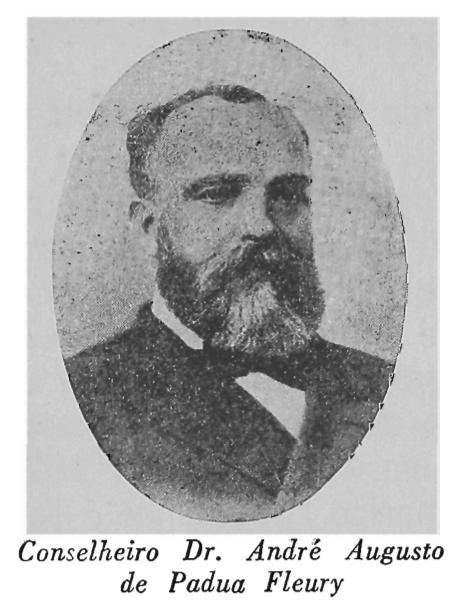
feito o curso do Collegio Pedro II, recebeu o grau de bacharel em sciencias e letras em 1848 e, no anno seguinte, matriculou-se no Curso Juridico de São Paulo. Bacharelou-se em 1853 e, logo, em 1854, foi nomeado juiz municipal em Goyaz.

Voltando á Côrte, exerceu alli a advocacia, ao mesmo tempo que servia na Secretaria de Estados dos Negocios da Justiça, na qual chegou a director geral. Commissionado pelo governo, foi á Europa estudar os diversos systemas penitenciarios, apresentando a respeito notavel estudo. Em 1860, foi membro da Commissão Inspectora da Casa de Correç̧ão. De 1878 a 1879, presidiu as provincias de Santa Catharina e do Ceará. Representou, na decima oitava legislatura, na Assembléa Legislativa, a provincia de Goyaz.

Occupou, no gabinete de 4 de julho, organizado pelo Visconde de Paranaguá, a pasta da Agricultura, Commercio e Obras Publicas.

Por decreto de 16 de janeiro de 1883, foi nomeado director da Faculdade de Direito de São Paulo, á qual prestou optimos serviços. Foi sob sua direç̧ão que o predio da Faculdade soffreu a reforma que the deu o aspecto que hoje tem, dotando-a de novo mobiliario, melhorando a bibliotheca, etc. 
Em 1885 foi eleito deputado geral por Matto Grosso. Aposentou-se, por decreto de 9 de agosto de 1890. Foi condecorado com o titulo de conselho.

\section{CONSELHEIRO Dr. CARLOS LEONCIO DA SILVA CARVALHO}

\section{(1890 a 1891)}

Filho do Dr. Carlos Antonio de Carvalho, nasceu na Côrte aos 18 de junho de 1847 .

Matriculou-se, em 1864, no primeiro anno do Curso

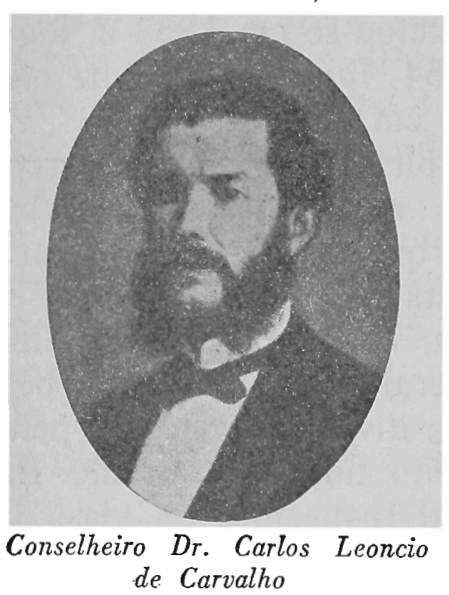
de Carvalho Juridico de São Paulo, bacharelando-se em 1868. No anno seguinte defendeu theses e recebeu o grau de doutor. Foi approvado plenamente. Inscreveu-se em concurso, em 1870, com Americo Brasiliense e José Joaquim de Almeida Reis. Classificado em terceiro logar, foi nomeado lente substituto, por decreto de 4 de janeiro de 1871, tomando posse em 3 de fevereiro seguinte.

Occupou a pasta do Imperio no gabinete de 5 de janeiro de 1878 , presidido pelo conselheiro Sinimbú.

De 1878 a 1880, foi deputado geral por São Paulo.

Por decreto de 7 de junho de 1881 , foi nomeado lente cathedratico de direito constitucional, das gentes e diplomacia. Tomou posse em 14 do mesmo mez. Por decreto de 31 de janeiro de 1885 foi nomeado bibliothecario da Faculdade de Direito, tomando posse em 4 de fevereiro.

Por decreto de 4 de outubro de 1890, foi nomeado director da Faculdade. 
Fez parte do Senado Paulista e do Congresso Constituinte, sendo um dos relatores da primeira Constituição de São Paulo.

Por decreto de 7 de fevereiro de 1895, foi designado para a cadeira de direito publico, na qual se jubilou, por decreto de 12 de janeiro de 1901 .

Mudou-se, então, para o Rio de Janeiro, onde professou na Faculdade Livre de Direito e onde falleceu aos 9 de fevereiro de 1912.

\section{CONSELHEIRO DR. JOAQUIM IGNACIO RAMALHO (Barão do Ramalho)}

\section{(1891 a 1902)}

Nasceu na cidade de São Paulo, aos 6 de janeiro de 1809. Filho do licenciado em cirurgia, José Joaquim de Souza Saquette, hespanhol, tornou-se filho adoptivo dos

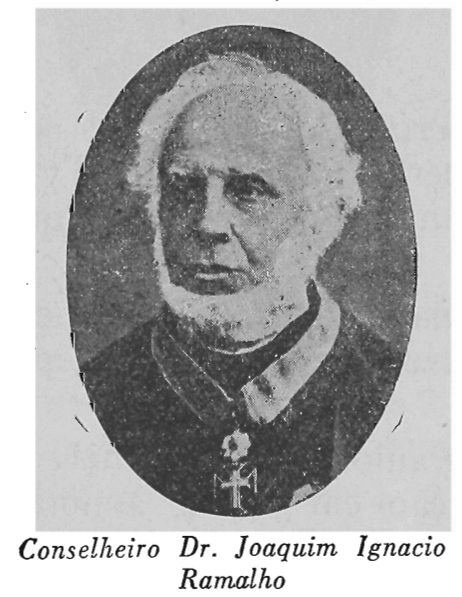
irmãos Antonio Nunes Rama-. tho e D. Anna Felisberta Ramalho, dos quaes tomou o sobrenome, e foi educado na velha escola dos rigidos costumes paulistas.

Cursava ainda o ultimo anno do curso juridico, em São Paulo, quando, a 3 de abril de 1834, foi nomeado lente substituto de philosophia racional e moral do Curso Annexo, cadeira de que se tornou proprietario em 22 de julho de 1836.

Bacharel em direito a 25 de outubro de 1834, recebeu o grau de doutor em 1835. Foi nomeado lente substituto da Faculdade de Direito por decreto de 23 de abril de 1836, tomando posse em 28 de maio do mesmo anno. Em 1845, foi vereador e presidente da Camara Municipal de 
São Paulo, de onde foi chamado á administração da provincia de Goyaz, por carta imperial de 16 de maio de 1845. Deputado geral pela provincia de Goyaz em 1848, foi, depois, em duas legislaturas, membro da Assembléa provincial de São Paulo. Pelos seus serviços, o governo, por carta de 1 de setembro de 1846, the fez mercê do officialato da Ordem da Rosa.

Por decreto de 8 de julho de 1854, foi nomeado lente cathedratico, e tomou posse da primeira cadeira do quinto anno, em 31 do mesmo mez.

Recebeu o titulo de conselho em 4 de dezembro de 1861 e a commenda de Nosso Senhor Jesus Christo, por decreto de 21 de maio de 1874.

Foi jubilado por decreto de 25 de agosto de 1883 e, por decreto de 25 de abril de 1891, nomeado director da Faculdade, cargo que exerceu até 15 de agosto de 1902, dia em que falleceu o Barão do Ramalho, com noventa e tres annos de edade, depois de uma das mais gloriosas existencias consagradas ao estudo, ao ensino e á pratica do direito.

Obras publicadas:

- Elementos de processo criminal, para uso das Faculdades de Direito do Imperio. São Paulo, Typographia Dois de Dezembro, de Antonio Louzada Antunes, 1856.

- Pratica civil e commercial. Typographia Imparcial, de Joaquim Roberto de Azevedo Marques, depois refundida em a

- Praxe Brasileira, São Paulo. Typographia do Ypiranga, 1869. Segunda edição em 1904, annotada pelo dr. Pamphilo d'Assumpção. São Paulo. Duprat \& Cia., 1904.

- Postillas de Pratica, Collecção completa das lições de Pratica do anno de 1865, precedidas de cinco lições de Hermeneutica Juridica e seguidas de dez de Processo Criminal, inteiramente correctas. $2 .^{a}$ edição. S. Paulo. Typographia Americana, 1872. 
- Instituições Orphanologicas, com uma carta do conselheiro João Chrispiniano Soares. S. Paulo, Typographia Jorge Seckler, 1874.

\section{DR. JOÃO PEREIRA MONTEIRO}

\section{(1903 a 1904)}

Filho de João Pereira Monteiro e de D. Maria Julia d'Azevedo Monteiro, nasceu na Côrte, aos 16 de maio de 1845. Trabalhou no commercio, que abandonou, para matricular-se no Collegio Pedro

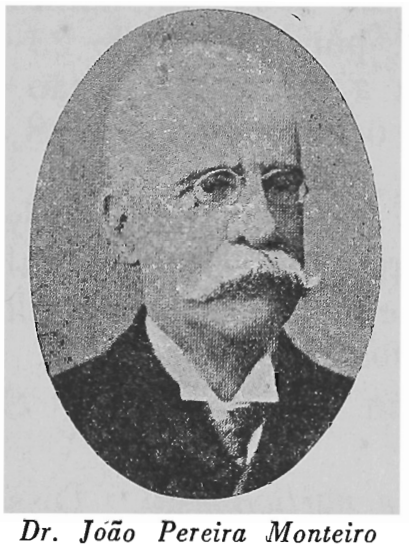
marca da capital de São Paulo. Oppoz-se a uma vaga de lente substituto da Faculdade de Direito, em 1881, e foi nomeado por decreto de 2 de setembro de 1882, sendo empossado no dia 6 desse mesmo mez. A dissertação, $O$ Perjurio, que para o concurso escreveu, teve largo successo. Por decreto de 15 de setembro de 1883, foi nomeado lente cathedratico, tomando posse da primeira cadeira do quinto anno, em 21 daquelle mesmo mez.

Em 1891, foi eleito deputado ao Congresso Legislativo Paulista.

Por decreto de 24 de janeiro de 1893, foi nomeado vice-director da Faculdade de Direito, e tomou posse em 7 
de março do mesmo anno. Pelo decreto de 7 de fevereiro de 1896, foi nomeado cathedratico de Theoria do Processo Civil, Commercial e Criminal e Pratica do Processo.

Inaugurando, em 1892, o curso de legislação comparada, proferiu a prelecção que corre impressa, Da Universalisação do Direito.

Em 1900, representou a Faculdade de Direito no Congresso Juridico Americano, ao qual apresentou a memoria A Unidade do Direito, em São Paulo impressa na Typographia Industrial.

Posto em disponibilidade em 1901, por effeito da reforma do ensino dos cursos juridicos, constante do decr. n. 3.903, de 12 de janeiro de 1901, foi nomeado director da Faculdade de Direito, por decreto de 23 de agosto de 1903, quando occorreu a morte do Barão de Ramalho, e nesse cargo a morte o encontrou em 18 de Novembro de 1904.

Além de innumeros trabalhos juridicos, que as revistas do seu tempo conservam, publicou João Monteiro valiosos trabalhos, que the deram grande nomeada, collocando-o na primeira plana dos jurisconsultos brasileiros

Paulo, 1882.

- Do Perjurio, dissertação de concurso. São

- Da sociedade em conta de participação. Dissertação de concurso.

- Da Universalisação do Direito. Prelecção inaugural da cadeira de legislação comparada. São Paulo, 1892.

- Organisação judiciaria. - Parecer sobre o Projecto da Organisação judiciaria de São Paulo, apresentado ao Senado Paulista. S. Paulo, 1891.

- Parecer sobre o Projecto n. ${ }^{\circ} 250$, de 1893. - Reforma do Codigo Penal, da Camara dos Deputados, pela Faculdade de Direito de São Paulo. São Paulo, 1893.

- Discursos (1890-1896) - São Paulo, 1897.

- Theoria do Processo Civil e Commercial, 3 volumes. 1. ${ }^{\mathrm{a}}$ ed., 1899-1901, 2. ${ }^{\mathrm{a}}$ ed., 1905; 3. ${ }^{\mathrm{a}}$ ed., 1912. $4 .^{2}$ ed., 192 . 
- Unidade do Direito. - Memoria apresentada ao Congresso Juridico Americano de 1900. - S. Paulo, 1900.

- Pareceres sobre os Projectos da Universidade do Rio de Janeiro, dos drs. Azevedo Sodré e Leoncio de Carvalho. - São Paulo, 1903.

- Applicaçóes do Direito. - Pareceres e promoções. 1. ${ }^{a}$ ed., São Paulo, 1904. — 2. ed., São Paulo, 1909.

Paulo, 1905.

- Direito das Acções. - Obra posthuma. - São

Em collaboração com o Conselheiro Dr. Manoel Duarte de Azevedo:

- Projecto do Codigo do Processo Criminal do Estado de São Paulo. - 1893.

- Projecto do Codigo do Processo Civil e Commercial. -1894 .

\section{DR. VICENTE MAMEDE DE FREITAS (1904 a 1908)}

Natural de São Paulo, filho de Joaquim Antonio de Freitas, matriculou-se no Curso Juridico em 1851 e bacharelou-se em 1855. Dedicado, desde muito moço, ao

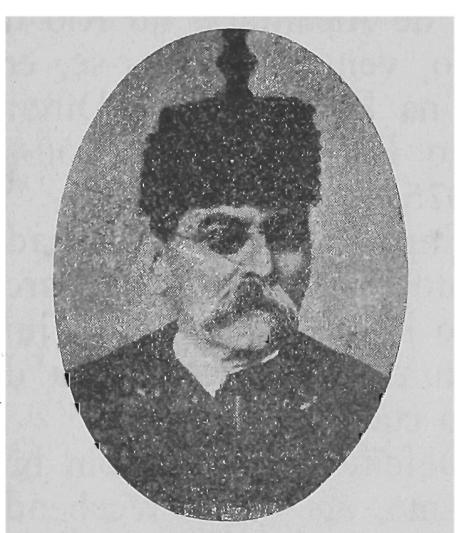

Dr. Vicente Mamede de Freitas magisterio, leccionou philosophia, historia, mathematica e as linguas latina, franceza e ingleza. No anno seguinte ao de sua formatura, dirigiu o Collegio Culto á Sciencia, que se tornou famoso. Fundou. depois, outro collegio na ladeira do Porto Geral, passando-o, posteriormente, ao Dr. Ivahy.

Defendeu theses e recebeu o grau de doutor em 1859.

Foi promotor publico em 1860 e occupou, nos biennios de 1864-65 e 1866-67, uma cadeira de deputado provincial. 
Como inspector geral da Instrucção Publica, inaugurou, em 2 de agosto de 1880, a Escola Normal de São Paulo.

Por decreto de 5 de setembro de 1882, approvado em concurso, foi nomeado lente substituto da Faculdade de Direito de São Paulo e, depois de ter feito um concurso anterior, do qual saiu nomeado o Dr. Sá e Benevides, tomou posse aos 13 do mesmo mez. Por decreto de 5 de maio de 1887 , foi nomeado lente cathedratico de direito civil, primeira cadeira do quarto anno, da qual tomou posse em 6, no dia immediato. Por decreto de 1 de novembro de 1902, foi nomeado vice-director e a 17 do mesmo mez se empossou. Por decreto de 7 de dezembro de 1904, foi nomeado director, na vaga, por fallecimento, do Dr. João Pereira Monteiro. Tomou posse no dia 13.

Falleceu aos 9 de agosto de 1908.

\section{Dr. ANTONIO DINO DA COSTA BUENO}

\section{(1908 a 1912)}

Natural de Pindamonhangaba, na provincia de São Paulo. Nasceu em 15 de dezembro de 1854.

Tendo estudado preparatorios no Collegio de São

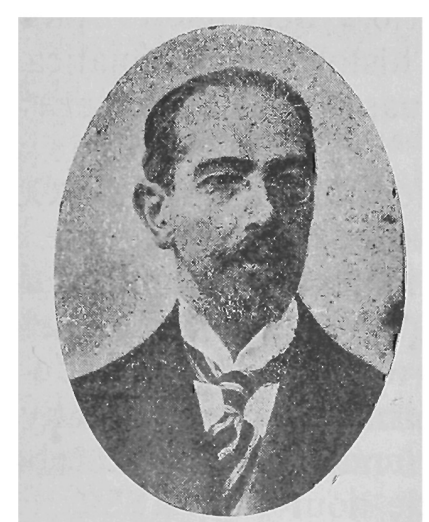

Pedro de Alcantara, no Rio de Janeiro, veiu matricular-se, em 1869, na Faculdade de Direito de São Paulo. Bacharelou-se em 1875.

Em 1876, foi nomeado promotor publico da comarca de São Paulo, e, em 1877, juiz substituto da primeira vara da mesma comarca.

Defendeu theses, com brilhantismo, em 1876, recebendo Dr. Antonio Dino da Costa Bueno o grau de doutor. Propoz-se a uma vaga de lente e, após cinco concursos, foi nomedo lente substituto por decreto de 5 de 
janeiro de 1883. Tomou posse em 9 do mesmo mez. Lente cathedratico por decreto de 6 de setembro de 1890 , da primeira cadeira do terceiro anno se empossou em 18 do mez seguinte. O decreto de 7 de fevereiro de 1896 lhe designou a cadeira de direito civil.

Em 1893, foi eleito deputado federal por São Paulo, bem assim em 1898.

Foi secretario do Interior, em 1896.

Aposentou-se, no cargo de director da Faculdade de Direito, por decreto de 18 de setembro de 1912, depois de ter remodelado as installações e mobiliario da Faculdade.

Membro e presidente da Commissão Directora do Partido Republicano Paulista, e presidente do Senado Paulista, assumiu a presidencia do Estado de São Paulo, em 28 de abril de 1927, como presidente do Senado Paulista, por fallecimento do presidente Carlos de Campos, exercendo o cargo até 14 de julho, data em que assumiu a presidencia o Dr. Julio Prestes de Albuquerque.

\section{DR. JOÃO MENDES DE ALMEIDA JUNIOR (1912 a 1915)}

Filho do jurisconsulto e politico Dr. João Mendes de Almeida e de D. Anna Rita Lobo Mendes de Almeida, nasceu na cidade de São Paulo, aos 30 de março de 1856.

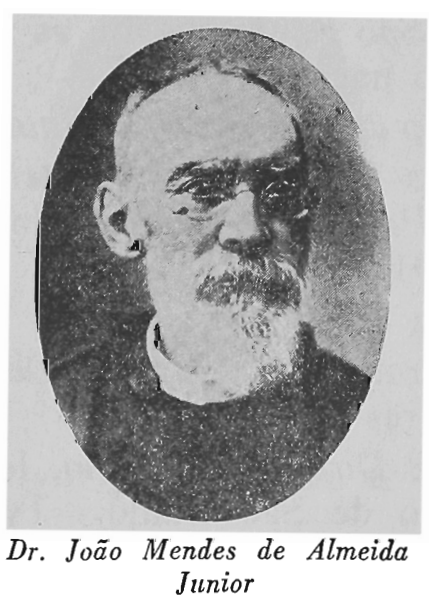

Junior

Feitos os preparatorios no Seminario Episcopal de São Paulo, matriculou-se na Faculdade de Direito de São Paulo, bacharelando-se em 1877. Approvado em defesa de theses, recebeu o grau de doutor em 2 de novembro de 1879. No anno seguinte foi eleito vereador municipal, servindo como presidente da Camara Municipal nos annos de 1881 e 1882 .

Militou na imprensa. Approvado em concurso, 
foi nomeado lente substituto da Faculdade de Direito, por decreto de 31 de agosto de 1889 , tomando posse aos 10 de setembro desse anno. Por decreto de 21 de março de 1891, foi nomeado lente cathedratico de pratica forense, quarta cadeira da quarta serie de Sciencias Juridicas, da qual tomou posse a 10 de abril seguinte. Por decreto de 7 de fevereiro de 1896, foi designado para reger a primeira cadeira de theoria do processo civil commercial e criminal, e pratica forense.

Em execução a lei organica de 1911, eleito director, em Congregação, em sessão de 29 de novembro de 1912, para o biennio 1913-14, exerceu o cargo até 7 de abril de 1915.

Por decreto de 11 de dezembro de 1916, foi nomeado ministro do Supremo Tribunal Federal, tomando posse a 5 de janeiro de 1917

Falleceu aos 25 de fevereiro de 1923, no Rio de Janeiro, de onde foi transportado para São Paulo e jaz no cemiterio da Consolação. Foi um dos maiores jurisconsultos brasileiros. Em homenagem aos seus grandes meritos, o Instituto da Ordem dos Advogados de São Paulo offereceu á Faculdade de Direito o seu busto em bronze, que se acha no seu Salão Nobre.

Além dos innumeros trabalhos, que publicou na $R e$ vista da Faculdade de Direito de São Paulo, deixou as seguintes obras, classicas no direito nacional.

- Monographia do Municipio da Cidade de S. Paulo;

- Exposição Preliminar das bases para a reforma judiciaria do Estado de São Paulo. Typ. Espindola, Siqueira \& Cia. São Paulo, 1901

- As Formas Organicas da Praxe Forense;

-O Proceso Criminal Brasileiro, 2 vols. Obra notavel, de que já foram dadas tres edições.

- Programma do Curso de Direito Judiciario, leccionado na Faculdade de Direito de São Paulo. Typ. Hennies Irmãos. São Paulo, 1910. Teve segunda edição augmentada em 1918. 
- Plano de Refórma Judiciaria, submettido ao Congresso Legislativo do Estado de São Paulo pelo Dr. Francisco de Paula Rodrigues Alves, Presidente do mesmo Estado. 3 vols. Typ. Siqueira. São Paulo, 1912.

- Golpes de Retrospecto. Prelecção de abertura da aula da primeira cadeira do quinto anno da Faculdade de Direito de S. Paulo, Typ. Hennies Irmãos. S. Paulo, 1913. 1914.

- O Ensino do Direito. Typ. Siqueira. S. Paulo,

- A uniformidade, a simplicidade $\epsilon$ a economia do nosso processo forense. Typ. Siqueira. São Paulo, 1915.

- Os indigenas do Brasil, seus direitos, individuaes e politicos.

- Climax ou escada do céu, obra de São João Climaco, que poz em vernaculo.

\section{DR. ULADISLAU HERCULANO DE FREITAS (1916 a 1925)}

Natural de Arroio Grande, provincia do Rio Grande do Sul, nasceu aos 25 de novembro de 1865, filho de Rogerio José de Freitas.

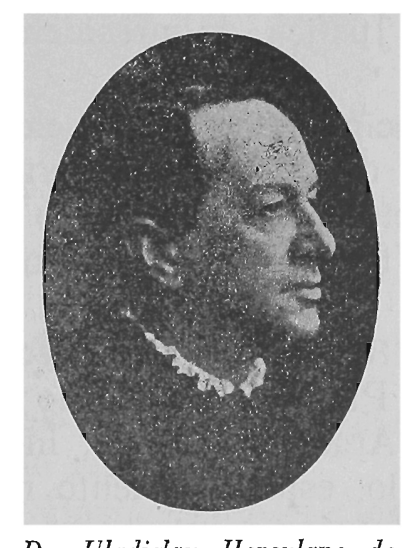

Dr. Uladislau Herculano de Freitas

Matriculado no primeiro anno da Faculdade de Direito de São Paulo em 1884, recebeu o grau de bacharel em 8 de março de 1889 , na mesma Faculdade, pois fez o quarto anno na Faculdade de Direito de Recife.

Advogado, jornalista e tribuno, fez longa carreira politica, ao lado de Francisco Glycerio, seu sogro.

Proclamada a Republica, exerceu o cargo de chefe de policia do Paraná e elaborou as bases da Constituição Politica daquelle Estado. 
Em 1890, foi nomeado lente substituto da Faculdade de Direito de São Paulo, por decreto de 30 de dezembro. Tomou posse e recebeu o grau de doutor em 16 de janeiro de 1891. Por decreto de 21 de março de 1891, foi nomeado lente cathedratico, leccionando a segunda cadeira da primeira serie de notariado, da qual tomou posse em 27 de abril daquelle anno.

Em 1896 foi eleito deputado estadual e, em 1894, deputado federal por São Paulo. Renunciou o mandato em 1895 e foi eleito senador estadual em 1896.

Nomeado lente cathedratico de direito criminal, por decreto de 10 de fevereiro de 1902, passou, por permuta com o dr. José Mariano Corrêa de Camargo Aranha, a lente cathedratico de direito publico e constitucional, por decreto de 1 de maio desse anno. Tomou posse em 6 de junho dessa cadeira e nella permaneceu por largo tempo, mas della constantemente affastado pelos seus deveres politicos.

Em 1910, foi nomeado delegado do Governo Federal no Congresso Juridico Pan-Americano, reunido em Buenos Aires.

De 11 de agosto de 1913 a 15 de novembro de 1914, exerceu o cargo de ministro da Justiça da presidencia Hermes da Fonseca.

Em Congregação de 4 de janeiro de 1915, foi eleito director da Faculdade de Direito de São Paulo para o biennio 1915-17, sendo, por decreto de 26 de março do mesmo anno nomeado director effectivo. Tomou posse a 8 de abril seguinte.

Em 14 de dezembro de 1918, foi nomeado secretario da Justiça e da Segurança Publica do Estado de São Paulo, na presidencia Altino Arantes e, então, inaugurou a Penitenciaria de São Paulo, estabelecimento modelar, tido como um dos mais adeantados do mundo, e lançou a pedra fundamental do Palacio da Justiça.

Em 1922, foi eleito senador estadual, e, logo depois deputado federal por São Paulo, tendo sido o relator da 
reforma constitucional levada a effeito sob a presidencia Arthur Bernardes.

Foi posto em disponibilidade no cargo de professor cathedratico, por decreto de 29 de agosto de 1925, e, nesse mesmo anno, por decreto de 7 de dezembro de 1925, foi nomeado ministro do Supremo Tribunal Federal.

Falleceu, no Rio de Janeiro, aos 14 de maio de 1926.

\section{DR. ANTONIO JANUARIO PINTO FERRAZ (1926)}

Natural de Campinas. Filho do Commendador Antonio Pinto Ferraz e de D. Maria das Dores de Souza Camargo Ferraz, nasceu aos 2 de julho de 1851.

Estudou as primeiras le-

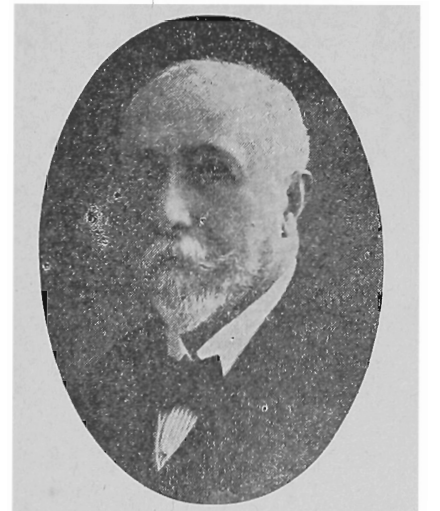
tras no Collegio Bressane, dirigido por Francisco de Paula Bressane e, depois, com o seu parente, Padre Miguel Archanjo Ribeiro de Castro Camargo. De Campinas veiu para São Paulo, a estudar no Lyceu Allemão, do Dr. Carlos Bartt, grande mathematico, e ahi aprimorou os seus estudos de lingua ingleza, com o dr. Morris. Dr. Antonio Januario Pinto Ferraz Estudou philosophia com o Dr. Galvão Bueno e frequentou o Curso Annexo á Faculdade de Direito, e nesta se matriculou em 1870.

Bacharelando-se em 1874, passou a advogar em São Paulo, com o conselheiro Dr. Martim Francisco e, depois, com o Dr. Antonio Carlos e Luiz Gama, vindo a ser o seu escriptorio o mais afamado de seu tempo. De muito deixou de advogar. 

vado.

Defendeu theses em 1878 e foi unanimemente appro-

Lente cathedratico de explicação succinta de direito patrio processual, primeira cadeira da segunda serie de notariado, por decreto de 21 de março de 1891, tomou posse em 27 de abril seguinte. Por decreto de 7 de fevereiro de 1896 , foi designado cathedratico de direito civil, cadeira que regeu até 29 de julho de 1925, data em que, por decreto, foi posto em disponibilidade.

Desde 1904 vem sendo, successivamente, eleito senador estadual.

Nomeado director da Faculdade de Direî́o, por decreto de 19 de maio de 1926, teve a fortuna de presidir, em 11 de agosto de 1927, as festas commemorativas do primeiro centenario da fundação dos cursos juridicos de São Paulo e de Olinda. 